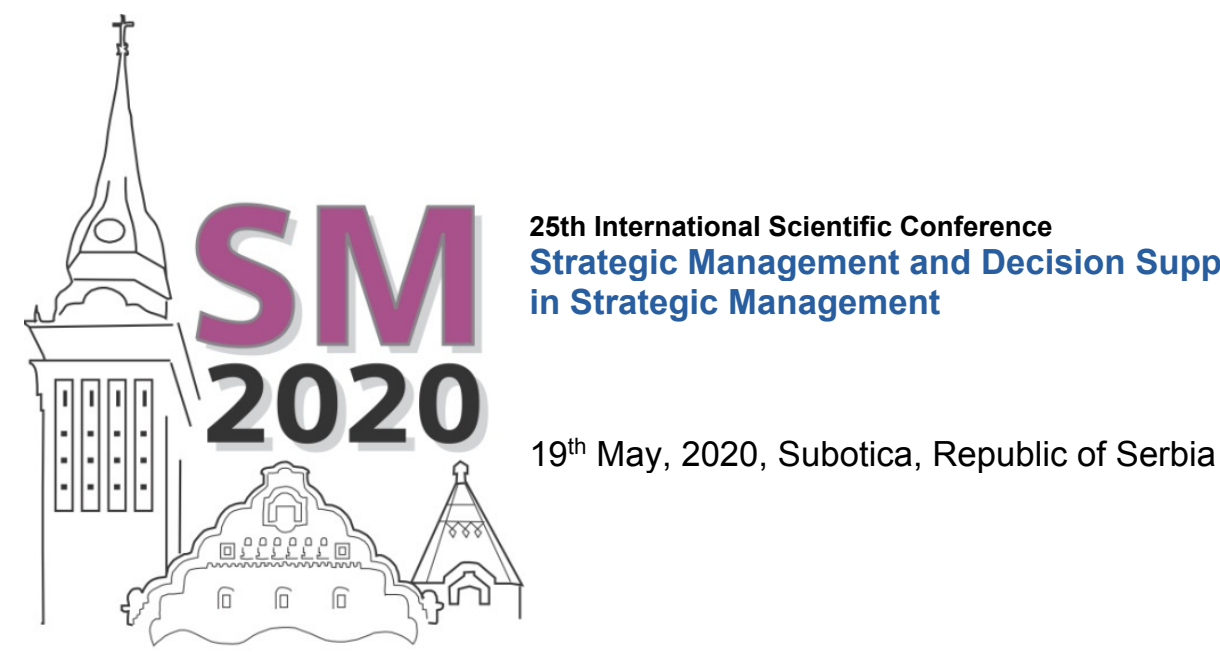

DOI: 10.46541/978-86-7233-386-2_1 Strategic Management and Decision Support Systems in Strategic Management

Jan Mendling

Vienna University of Economics and Business, Vienna, Austria

jan.mendling@wu.ac.at

\section{Brian Pentland}

Michigan State University,

East Lansing, MI, United States of America

pentland@broad.msu.edu

\author{
Jan Recker \\ University of Cologne \\ Cologne, Germany \\ jan.recker@wiso.uni-koeln.de
}

\title{
THE CONVERGENCE OF BUSINESS PROCESS MANAGEMENT AND DIGITAL INNOVATION
}

\begin{abstract}
Business process management is a prolific field of research and an area of strong industrial uptake with roots in both management science and information systems engineering. Traditionally, business process management has largely been utilized in an inward-looking way with the aim to improve operations, eliminate waste, and increase efficiency. Recent developments around digital innovation challenge conventional ideas of process reengineering with a strong emphasis on the external market and exploration. In this talk, we will discuss the complementarity of BPM and digital innovation.
\end{abstract}

Keywords: business process management, digital innovation

\section{KEY ASSUMPTIONS OF BPM AND DIGITAL INNOVATION}

Business process management is the field of research focusing on the design, analysis, implementation and monitoring of business processes by the help of methods, techniques and tools (Dumas et al. 2018). The traditional focus of BPM research has been on automation and efficiency, among others by eliminating waste, utilizing information systems, and automatic analysis techniques. Digital innovation is concerned with phenomena that emerge from the use of digital technologies and platforms for interaction and coordination. The key in this regard is its power to unleash generative capacity (Tilson, Lyytinen \& Sørenson 2010). Both BPM and digital innovation are concerned with performance, but with an emphasis on the opposite ends of the spectrum between operational efficiency and generative capacity.

Mendling, Pentland \& Recker (2020) highlight four major differences in the key assumptions of BPM and digital innovation.

1. Design and Solution Space: While BPM strongly advocates a separation of problem an solution space (as-is process modeling versus to-be process modeling), digital innovation emphasizes the co-evolution of problem and solution space with none of them being fix at a given point in time.

2. Design versus Emergence: While classical BPM is rolled out in a top-down fashion, digital innovation largely emerges bottom-up with generativity arising from the small.

3. Temporality: While BPM defines a strict design process with discrete stages, digital innovation often unfolds in an ad-hoc fashion driven by situational opportunities.

4. Boundedness: While BPM is bounded to an organizational context, digital innovation is a process that spans organizations and is in essence unbounded. 


\section{CONVERGENT ASSUMPTIONS OF BPM AND DIGITAL INNOVATION}

The tension between the key assumptions of BPM and digital innovation can be a fertile starting point to challenge established assumptions. Mendling, Pentland \& Recker (2020) formulate four propositions on how BPM and digital innovation can converge.

1. Design and Solution Space: Over time, process design has to balance new feature innovation with immediate feedback. Indeed, it is impossible to fully anticipate how well a process design will work but it is also impossible to fully anticipate which process patterns will emerge without design. For this reason, approaches supporting BPM in an agile way and technologies such as AB-testing and light-weight automation will become more important.

2. Design versus Emergence: Over time, process design has to balance predefined structure and freedom for adaptation. Indeed, it is impossible to fully specify processes beforehand but some design is necessary to lend structure. For this reason, approaches supporting flexibility for BPM and corresponding technologies will become more important.

3. Temporality: Over time, process management has to balance enforcement of process compliance with identification of positive deviance. Indeed, it is impossible to anticipate how a process will be performed tomorrow but some continuous understanding will be required about what the process-as-performed currently looks like. For this reason, approaches supporting monitoring and data-driving analysis such of business processes as process mining with become more important.

4. Boundedness: Over time, process design has to balance local optimization and global options for reuse. Indeed, it is impossible to fully anticipate how processes are integrated and reused in emerging value-creation networks but all processes will be embedded in and personalized experiences to some extent. For this reason, approaches for inter-organizational coordination such as blockchains and a focus on reuse as with microservice architectures will become more important in the future.

\section{CONCLUSIONS}

In this paper, we have summarized the key arguments of Mendling, Pentland \& Recker (2020) about the assumptions of BPM and digital innovation and the opportunities for the two fields to converge. Clearly, BPM and digital innovation are two sides of the same coin. Processes, technologies and products are intertwined. Future research should capitalize on the complementarity by building on both discourses.

\section{REFERENCES}

Dumas, M., La Rosa, M., Mendling, J., Reijers, H.A. (2018): Fundamentals of Business Process Management. Second Edition. Springer-Verlag. DOI: 10.1007/978-3-662-56509-4

Mendling, J., Pentland, B., \& Recker, J. (2020): Building a Complementary Agenda for Business Process Management and Digital Innovation. European Journal of Information Systems. DOI: 10.1080/0960085X.2020.1755207.

Tilson, D., Lyytinen, K., \& Sørensen, C. (2010). Digital infrastructures: The missing is research agenda. Information Systems Research, 21(4), 748-459. DOI: 10.1287/isre.1100.0318 